\title{
Diagnostic features of transfusion associated graft versus host disease
}

\author{
A L Appleton, L Sviland, A D J Pearson, J Wilkes, M A Green, A J Malcolm
}

\begin{abstract}
Aims-To define the immunopathological profile of transfusion associated graft versus host disease (TA-GvHD) to elucidate its pathophysiology and to determine if any features are of diagnostic value.

Methods-Nine patients (age range 14-61 years) who developed histologically confirmed TA-GvHD between 1989 and 1992 were studied. Immunohistochemical analysis of frozen and formalin fixed skin biopsy tissue was performed. Sections were stained with antibodies to CD3, CD8, CD4 and HLA-DR, using a routine streptavidin-biotin technique with standard diaminobenzidine development.

Results-All biopsy specimens showed aberrant positive expression of HLA-DR by epidermal keratinocytes. In four patients, all of whom died, HLA-DR was diffusely expressed throughout the epidermis; in the other five cases keratinocyte expression of HLA-DR was more focal. In all biopsy specimens $T$ cells had infiltrated the dermis and epidermis. In all nine cases $\mathrm{CD} 4+\mathrm{T}$ helper/inducer cells were the predominant $T$ cells.

Discussion-Immunohistochemical studies are of value in the diagnosis of TA-GvHD. Aberrant keratinocyte expression of HLA-DR and dermal and epidermal infiltration of CD4 $+T$ cells are immunopathological features of TAGvHD. Immunohistochemical analysis of skin biopsy tissue using antibodies to these markers is thus a useful investigation in pancytopenic patients presenting with unexplained rashes.
\end{abstract}

( 7 Clin Pathol 1994;47:541-546)

Department of Pathology, University of Newcastle Upon Tyne, Royal Victoria Infirmary, Newcastle upon Tyne, NE1 4LP A L Appleton L Sviland I Wilkes

M A Green

A J Malcolm

Department of Child Health

A D J Pearson

Correspondence to: Dr A L Appleton (née McCarthy)

Accepted for publication 14 December 1993
Graft versus host disease (GvHD) is most commonly seen after allogeneic bone marrow transplantation (BMT). ${ }^{1}$ Transfusion associated GvHD (TA-GvHD) following transfusion of non-irradiated blood products in patients with naturally occurring or acquired immune deficiency or suppression is also a well recognised phenomenon. ${ }^{23}$ With the increasing intensity of treatment for malignancies in both children and adults, TAGvHD is emerging as an increasingly serious problem.

TA-GvHD has a similar clinical presentation to BMT related GvHD - a diffuse erythematous maculopapular rash affecting predominantly proximal areas, typically ensu- ing six to 10 days after transfusion. However, it has a different clinical course, with a higher mortality and a more rapid and more fulminant course. ${ }^{34}$ In contrast to BMT related GvHD, in which marrow aplasia is less pronounced because the marrow is donor derived, TA-GvHD is associated with profound pancytopenia and striking marrow hypocellularity. ${ }^{56}$ In the liver TA-GvHD causes diffuse parenchymal injury, ${ }^{7}$ in contrast to the isolated biliary epithelial changes associated with the hepatic disease associated with BMT related GvHD. Irradiation of blood products has been shown to abrogate TAGvHD, and its use in the management of immunosuppressed patients is recommended, ${ }^{8}$ but the dose of radiation required to prevent GvHD while maintaining the viability of the blood product remains contentious. ${ }^{9}$ Furthermore, cases of TA-GvHD have been described despite use of irradiated products. ${ }^{10}$

The prognosis of TA-GvHD is currently poor. However, treatment at an early stage may be associated with a better prognosis. Early accurate diagnosis is therefore essential. Unfortunately, it is often difficult to distinguish the features of TA-GvHD from other conditions such as drug eruptions and viral infections. $^{3}$ Patients receiving intensive chemotherapy for malignancy frequently develop non-specific skin rashes and gastrointestinal disturbances, and in the absence of clear guidelines for diagnosis, TA-GvHD is probably underdiagnosed, with resulting morbidity and mortality.

This study was undertaken to identify the diagnostic features of TA-GvHD and to clarify the pathophysiology of this condition. We have already shown that immunohistochemical studies are useful in the diagnosis of BMT related GvHD, ${ }^{11}{ }^{12}$ demonstrating that aberrant expression of HLA class II antigens (HLA-DR) is an immunopathological feature of acute GvHD and is of diagnostic value. No immunohistochemical studies of TA-GvHD have been reported before, although the histopathology is well documented. ${ }^{13}$ Immunohistochemical analysis of skin biopsy tissue from nine patients with histologically confirmed TA-GvHD was thus performed to establish the immunopathological profile of this condition.

\section{Methods}

Nine patients who presented to the Royal Victoria Infirmary, Newcastle Upon Tyne, between April 1989 and April 1992 were 
Table 1 Patient details

\begin{tabular}{llll}
\hline Case No & Age $(y)$ & Primary disease & Chemotherapy \\
\hline 1 & 61 & CLL & Fludarabine \\
2 & 53 & NHL & Daunorubicin, cyclophosphamide, vincristine \\
3 & 47 & CLL & Fludarabine \\
4 & 17 & Ewing's sarcoma & Ifosfamide, VP16, cyclophosphamide \\
5 & 14 & Ewing's sarcoma & Ifosfamide, mesna, vincristine, doxorubicin \\
6 & 14 & ALL & Cyclophosphamide, vincristine, doxorubicin \\
7 & 59 & ALL & Cytosine, vincristine, doxorubicin \\
8 & 39 & AML & DAT, MACE, MidAC \\
9 & 18 & ALL & Mitomycin C, mitozantrone, methotrexate \\
\hline
\end{tabular}

CLL: chronic lymphocytic leukaemia; NHL: non-Hodgkin's lymphoma; AML: acute myeloblastic leukaemia; ALL: acute lymphoblastic leukaemia; DAT: daunorubicin, cytarabine, thioguanine; MACE: M-amsacrine, cytarabine, etoposide; MidAC: mitozantrone, cytarabine

Table 2 Patients' peripheral blood parameters at transfusion

\begin{tabular}{lccclll}
\hline $\begin{array}{l}\text { Case } \\
\text { No }\end{array}$ & $\begin{array}{l}\text { White } \\
\text { cells }\end{array}$ & \multicolumn{2}{c}{$\begin{array}{c}\text { Lymphocytes } \\
\left(\times 10^{9} / \mathrm{l}\right)\end{array}$} & Meutrophils & $\begin{array}{l}\text { Platelets } \\
\left(\times 10^{\circ} / \mathrm{l}\right)\end{array}$ & $\begin{array}{l}\text { Haemoglobin } \\
(\mathrm{g} / \mathrm{L})\end{array}$ \\
\hline 1 & $4 \cdot 8^{\star}$ & $4 \cdot 6$ & 0 & $0 \cdot 2$ & 86 & 102 \\
2 & $0 \cdot 3$ & $0 \cdot 2$ & 0 & $0 \cdot 1$ & 11 & 89 \\
3 & $13 \cdot 9^{\dagger}$ & $13 \cdot 8$ & $0 \cdot 1$ & 0 & 27 & 79 \\
4 & $0 \cdot 1$ & $0 \cdot 1$ & 0 & 0 & 10 & 75 \\
5 & $0 \cdot 1$ & $0 \cdot 1$ & 0 & 0 & 31 & 97 \\
6 & $0 \cdot 2$ & $0 \cdot 1$ & $0 \cdot 1$ & 0 & 27 & 53 \\
7 & $1 \cdot 6$ & $0 \cdot 3$ & $1 \cdot 2$ & $0 \cdot 1$ & 41 & 120 \\
8 & $0 \cdot 4$ & $0 \cdot 4$ & 0 & 0 & 10 & 74 \\
9 & $0 \cdot 5$ & $0 \cdot 5$ & 0 & 0 & 11 & 97 \\
\hline
\end{tabular}

Reference ranges: White cells: 4-11 $\times 10^{9} / 1$; lymphocytes: $1.3-3.5 \times 10^{9} / 1$; neutrophils: $2 \cdot 0-7 \cdot 5 \times$ $10^{9} / 1$; monocytes: $0 \cdot 2-0 \cdot 8 \times 10^{9} / 1$; platelets: $150-400 \times 10^{9} / 1$.

$\star 130$ at onset of treatment.

+128 at onset of treatment. leukaemia developed a diffuse erythematous maculopapular rash on the trunk, abdomen, and palms, which was clinically consistent with GvHD, 10 days after transfusion of nonirradiated blood products for pancytopenia secondary to fludarabine treatment. A skin biopsy specimen from the abdomen was consistent with severe GvHD (Lerner grade III). ${ }^{14}$ $\mathrm{He}$ responded poorly to high dose intravenous methylprednisolone and died of GvHD related liver failure five days later.

Case 2

A 53 year old man with non-Hodgkin's lymphoma received non-irradiated blood products for pancytopenia secondary to daunorubicin, cyclophosphamide, and vincristine treatment. He developed jaundice and an extensive dusky erythematous macular rash on the trunk, arms, and shoulders seven days after his last transfusion, one month after starting chemotherapy. A skin biopsy specimen from the shoulder was consistent with moderately severe GvHD (grade II). He was treated with intravenous methylprednisolone but responded poorly and died of GvHD induced liver failure eight days later.

\section{Case 3}

A 47 year old man with chronic lymphocytic leukaemia developed diarrhoea and a severe diffuse erythematous rash on his back, trunk, and palms 10 days after a transfusion of nonirradiated blood products for pancytopenia secondary to fludarabine treatment. A skin biopsy specimen from the trunk was consistent with moderately severe GvHD (grade II). $\mathrm{He}$ was treated with high dose intravenous methylprednisolone, to which he initially responsed, but he deteriorated and died 10 days later of GvHD induced liver failure.

\section{Case 4}

A 17 year old girl with a relapsed primitive neuroectodermal tumour (Ewing's sarcoma) of the upper humerus developed an extensive macular rash on the trunk, back, and abdomen six days after transfusion of 3 units of non-irradiated blood products for pancytopenia secondary to second line chemotherapy (ifosfamide, etoposide, and cyclophosphamide). A skin biopsy specimen from the trunk was consistent with moderately severe GvHD (grade II). She responded poorly to high dose intraveous methylprednisolone and died of liver failure five days later.

\section{Case 1}

A 61 year old man with chronic lymphocytic

Table 3 Patients' peripheral blood parameters at onset of rash

\begin{tabular}{|c|c|c|c|c|c|c|c|c|c|}
\hline \multirow{2}{*}{$\begin{array}{l}\text { Case } \\
\text { No } \\
\end{array}$} & \multirow{3}{*}{$\begin{array}{c}\begin{array}{c}\text { White } \\
\text { cells }\end{array} \\
4 \cdot 4 \\
0.6\end{array}$} & \multicolumn{2}{|c|}{$\begin{array}{c}\text { Lymphocytes Neutrophils } \\
\left.\qquad \times 10^{\prime} / l\right)\end{array}$} & \multirow{3}{*}{$\begin{array}{l}\text { Monocytes } \\
0 \cdot 1 \\
0 \cdot 1\end{array}$} & \multirow{2}{*}{$\begin{array}{l}\begin{array}{l}\text { Platelets } \\
\left(\times 10^{\circ} / l\right)\end{array} \\
93\end{array}$} & \multirow{2}{*}{$\begin{array}{l}\begin{array}{l}\text { Haemoglobin } \\
\text { g/l }\end{array} \\
128\end{array}$} & \multirow{2}{*}{$\begin{array}{c}\begin{array}{c}\text { Bilimubin } \\
(\mu \text { molll })\end{array} \\
50\end{array}$} & \multirow{2}{*}{$\begin{array}{l}\begin{array}{l}\text { Alkaline } \\
\text { phosphatase (Ull) }\end{array} \\
235\end{array}$} & \multirow{2}{*}{$\begin{array}{l}\begin{array}{c}A L T \\
(U / l)\end{array} \\
308\end{array}$} \\
\hline & & $4 \cdot 3$ & 0 & & & & & & \\
\hline & & 0.4 & 0.1 & & & 139 & 103 & & \\
\hline & $10 \cdot 4$ & $10 \cdot 3$ & $10 \cdot 1$ & 0 & 14 & 89 & 22 & 157 & 84 \\
\hline & & $0 \cdot 3$ & 0.2 & 0.1 & 10 & 71 & 28 & 179 & 147 \\
\hline & 0.3 & $0 \cdot 3$ & & 0 & 30 & 87 & 43 & 1013 & 78 \\
\hline & 0.3 & $0 \cdot 2$ & $0 \cdot 1$ & 0 & 26 & 79 & 17 & 145 & 36 \\
\hline & $2 \cdot 6$ & 1.4 & $1 \cdot 2$ & 0 & 67 & 143 & 20 & 271 & 22 \\
\hline & 0.5 & 0.5 & 0 & 0 & 77 & 100 & 12 & 68 & 47 \\
\hline & 0.6 & $0 \cdot 6$ & 0 & 0 & 12 & 127 & 11 & 63 & 54 \\
\hline
\end{tabular}

Reference range: bilirubin: 3-19 $\mu \mathrm{mol} / 1$; alkaline phosphatase: $29-111 \mathrm{U} / \mathrm{l}$; alanine-amino transferase: 3-41 U/1. 
Table 4 Severity of GvHD and outcome

\begin{tabular}{|c|c|c|c|}
\hline $\begin{array}{l}\text { Case } \\
\text { No }\end{array}$ & $\begin{array}{l}\text { GvHD grade } \\
\text { (skin biopsy) }\end{array}$ & $\begin{array}{l}\text { gastrointestinal tract/liver } \\
\text { involved? }\end{array}$ & Outcome \\
\hline $\begin{array}{l}1 \\
2 \\
3 \\
4 \\
5\end{array}$ & $\begin{array}{l}\text { III } \\
\text { II } \\
\text { II } \\
\text { II } \\
\text { II }\end{array}$ & $\begin{array}{l}\text { Liver } \\
\text { Liver } \\
\text { Gastrointestinal tract + liver } \\
\text { Liver } \\
\text { Gastrointestinal tract + liver }\end{array}$ & $\begin{array}{l}\text { Died of liver failure } 5 \text { days later } \\
\text { Died of liver failure } 8 \text { days later } \\
\text { Died of liver failure } 14 \text { days later } \\
\text { Died of liver failure } 5 \text { days later } \\
\text { Died of gastrointestinal bleed } \\
\quad 14 \text { days later }\end{array}$ \\
\hline $\begin{array}{l}6 \\
7 \\
8 \\
9\end{array}$ & $\begin{array}{l}\text { II } \\
\text { II } \\
\text { II } \\
\text { II }\end{array}$ & $\begin{array}{l}\text { No } \\
\text { No } \\
\text { No } \\
\text { No }\end{array}$ & $\begin{array}{l}\text { Died of aspergillosis } 2 \text { days later } \\
\text { Survived } \\
\text { Survived } \\
\text { Survived }\end{array}$ \\
\hline
\end{tabular}

Table 5 Immunohistochemical results

\begin{tabular}{llll}
\hline $\begin{array}{l}\text { Case } \\
\text { No }\end{array}$ & $\begin{array}{l}\text { HLA-DR } \\
\text { (keratinocyte expression) }\end{array}$ & $\begin{array}{l}\text { T cell } \\
\text { infiltrate }\end{array}$ & $\begin{array}{l}\text { Predominant } \\
\text { T cell subset }\end{array}$ \\
\hline 1 & +, diffuse & yes & T4 \\
2 & +, diffuse & yes & T4 \\
3 & +, focal & yes & T4 \\
4 & +, diffuse & yes & T4 \\
5 & +, diffuse & yes & T4 \\
6 & +, focal & yes & T4 \\
7 & +, focal & yes & T4 \\
8 & +, focal & yes & T4 \\
9 & +, focal & yes & T4 \\
\hline
\end{tabular}

Case 5

A 14 year old girl with a primitive neuroectodermal tumour (Ewing's sarcoma) of the right scapula developed an extensive erythematous macular rash, palmoplantar erythema, and diarrhoea and abdominal pains nine days after transfusion of non-irradiated blood products for pancytopenia secondary to ifosfamide, mesna, vincristine and doxorubicin treatment. A skin biopsy specimen from the trunk was consistent with moderately severe GvHD (grade II). A rectal biopsy specimen also showed GvHD, with extensive single cell necrosis of glandular crypt cells. She was treated with high dose intravenous methylprednisolone and oral prednisolone, and later cyclosporine A, but responded poorly. The rash became worse, with necrosis of large areas of skin. The diarrhoea persisted and the jaundice deepened, with deterioration of her liver function tests. Thalidomide and antiinterleukin-2 receptor (IL-2R) antibody were administered as second line treatment. However, shortly afterwards she sustained a massive gastrointestinal bleed, thought to be secondary to thrombocytopenia at least partly related to GvHD induced myelosuppression, and she died 14 days after the onset of the rash.

\section{Case 6}

A 14 year old girl with acute lymphoblastic leukaemia developed an erythematous maculopapular rash on the abdomen three days after transfusion of 3 units of non-irradiated blood products for pancytopenia secondary to cyclophosphamide, vincristine, and doxorubicin treatment. A skin biopsy specimen from the abdomen was consistent with moderately severe GvHD (grade II). Before treatment for GvHD could be initiated, she had a cardiorespiratory arrest, and she died two days after the onset of the rash. The cause of death was found to be invasive pulmonary aspergillosis secondary to pancytopenia, partly related to GvHD induced myelosuppression.
Case 7

A 59 year old man with acute lymphoblastic leukaemia developed a diffuse erythematous rash on the trunk and abdomen nine days after transfusion of non-irradiated buffy coat for pancytopenia secondary to chemotherapy. A skin biopsy specimen from the trunk was consistent with moderately severe GvHD (grade II). He responded well to intravenous methylprednisolone, although he later relapsed and died six months later.

Case 8

A 39 year old woman with acute myeloblastic leukaemia developed an erythematous rash on her back and trunk eight days after transfusion of 3 units of non-irradiated packed cells for pancytopenia secondary to danorubicin, cytarabine, thioguanine, $\mathbf{M}$-amsacrine, cytarabine, etoposide, and mitozantrone, cytarabine treatment (table 1). A skin biopsy specimen from the lower back was consistent with moderately severe GvHD (grade II). She responded well to high dose intravenous methylprednisolone, continuing on the chemotherapy with irradiated blood product support. She is currently stable at the time of writing.

\section{Case 9}

An 18 year old girl with acute lymphoblastic leukaemia developed a diffuse erythematous maculopapular rash on the back, trunk, arms and hands seven days after transfusion of nonirradiated blood products for pancytopenia secondary to mitomycin C, mitozantrone, and methotrexate treatment which had begun 19 days previously. A skin biopsy specimen from the upper back was consistent with moderately severe GvHD (grade II). She responded well to intravenous methylprednisolone and received further chemotherapy (vincristine and mercaptopurine) with irradiated blood product support. She subsequently relapsed and died 12 months later.

\section{HISTOLOGICAL AND IMMUNOHISTOCHEMICAL} PROCESSING

All biopsy specimens were taken within 24 hours of the onset of rash. Punch biopsy specimens were taken from lesional tissue under aseptic technique. In four of the cases (Nos $2,5,6,7)$ tissue was obtained fresh and in duplicate, and in these cases each biopsy specimen was bisected to produce four pieces of tissue-one each for routine histological processing, immunohistochemical analysis, viral culture and polymerase chain reaction (PCR) analysis for viral DNA, to exclude viral exanthem. In the other five cases (Nos $1,3,4,8,9)$ the tissue was received fixed in formalin, necessitating modified immunohistochemical analysis of these patients.

All biopsy specimens were formalin fixed and stained with haematoxylin and eosin. Sections were assessed for features of GvHD, as described by Lerner et al. ${ }^{14}$ Grade I is focal or diffuse vacuolar degeneration of basal epidermal cells, with or without an inflammatory infiltrate, grade II eosinophilic degeneration of scattered dead keratinocytes, producing 
Figure 1 Skin biopsy specimen from case 1 with specimen from case 1 with epidermal keratinocyte expression of $H L A-D R$ (standard $D A B$ development); $\boldsymbol{e}=$ epidermis $\boldsymbol{d}=$ dermis.

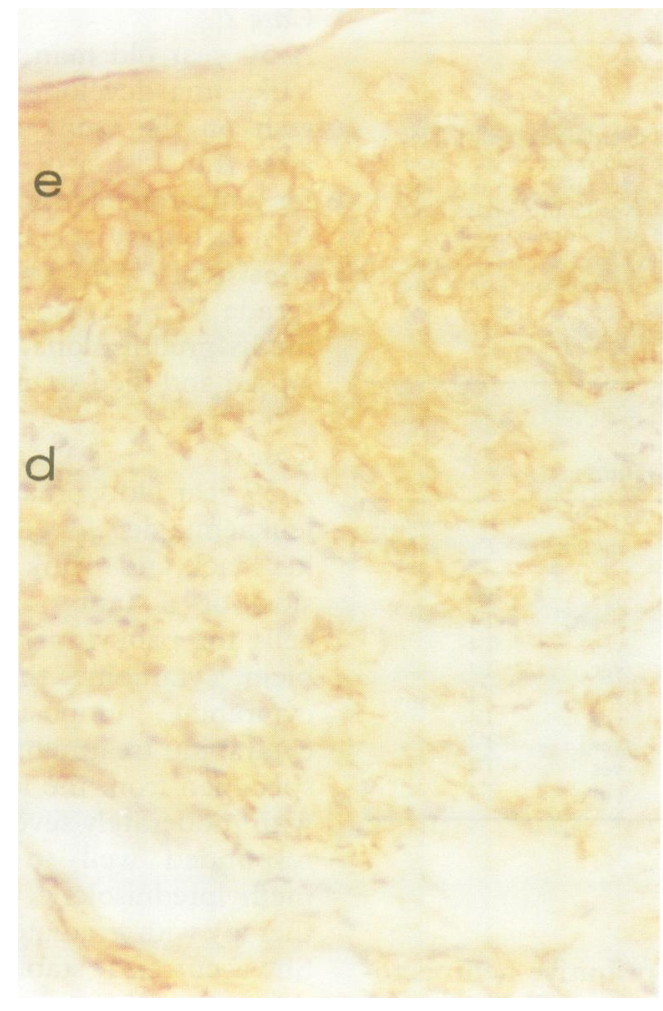

"eosinophilic" (dyskeratotic) bodies containing brightly eosinophilic cytoplasm and pyknotic nuclei; grade III extensive basal epidermal degeneration, with splitting along the dermo-epidermal junction; and grade IV extensive skin damage, with sloughing of the epidermis.

Fresh skin biopsy specimens were snapfrozen. Cryostat sections were stained with monoclonal antibodies recognising class II
Figure 2 Skin biopsy specimen from case 5 with $T A-G v H D$, showing predominance of $C D 4+$ cells (standard $D A B$ development);

$\boldsymbol{e}=$ epidermis, $\boldsymbol{d}=$ dermis.
HLA antigen (HLA-DR, Becton Dickinson), CD3 pan $T$ cell marker (leu 4; Becton Dickinson), CD8 $\mathrm{T}$ cytotoxic/suppressor cell marker (OKT8, OrthoDiagnostics) and CD4 $\mathrm{T}$ helper/inducer cell marker ( $\mathrm{T} 4$, Silenus), using a routine streptavidin-biotin technique with standard diaminobenzidine (DAB) development. Formalin fixed, paraffin wax embedded sections were stained with antibodies to HLA-DR (CR3-43; Dakopatts), (CD3, Dakopatts), and CD8 (CD8, Dr David Mason), ${ }^{15}$ using a routine streptavidin-biotin method for paraffin wax sections. $T$ cells were distinguished in the paraffin wax-embedded sections using anti-CD3. Distribution of the $T$ cell subsets was determined by comparing the distribution of $\mathrm{CD} 3+$ cells with the distribution of CD8 + cells, because no antigen for CD4 antibody suitable for use on fixed tissue is currently available and microwave antigen retrieval proved unsuccessful for this antigen. Microwave antigen retrieval ${ }^{16}$ was performed for anti-CD8: dewaxed sections were immersed in methanol/peroxide for 20 minutes, heated in citrate buffer in a microwave oven for five minutes twice, incubated overnight in primary antiserum and stained using routine streptavidin-biotin. HLA-DR and CD8 were developed using standard $\mathrm{DAB}$, while $\mathrm{CD} 3$ was developed using nickel-modified DAB with post-development enhancement in TRIS/cobalt to reduce background staining. ${ }^{17}$

\section{Results (table 5)}

Biopsy specimens from all of the patients showed aberrant expression of HLA-DR by epidermal keratinocytes, in addition to normal expression by antigen presenting cells in the dermis (fig 1). In four of the patients (Nos $1,2,4,5)$ keratinocyte expression of HLA-DR was densely and diffusely positive throughout the epidermis. In the other five cases keratinocyte expression of HLA-DR was more focal.

Infiltration of the dermis and epidermis by $T$ cells was noted in all the biopsy specimens, as determined by inflammatory cell expression of either leu 4 (cases 2,5,6,7), or CD3 (cases $1,3,4,8,9)$. In all nine cases CD4 $+\mathrm{T}$ cells were the predominant subset. In cases $2,5,6$ and $7, \mathrm{CD} 4+$ cells were seen in greater numbers than CD8 + cells in both the dermis and epidermis (fig 2). In cases $1,3,4,8$ and 9 comparative analysis of CD8 + cells with CD3 + cells revealed only scanty CD8 + cells, despite large numbers of cells expressing the pan $T$ cell marker (fig 3), suggesting that most infiltrating $\mathrm{T}$ cells were of the CD4 + T helper/inducer subset.

\section{Discussion}

All nine patients studied had a skin rash; five patients also had liver dysfunction, two of whom also had lower gastointestinal GvHD. Six of the nine patients died, including all five patients with liver dysfunction. The tendency for TA-GvHD to have a fulminant course, which is clearly illustrated by this study, 
Figure 3 Formalin fixed skin biopsy specimen from case 3 with TA-GvHD, showing florid $C D 3+$ infiltration (above) (nickelmodified $D A B$ with postdevelopment enhancement in TRIS-cobalt, compared with scanty $C D 8+$ cells (below) (standard $D A B$ development); $\boldsymbol{e}=$ epidermis, $\boldsymbol{d}=$ dermis.

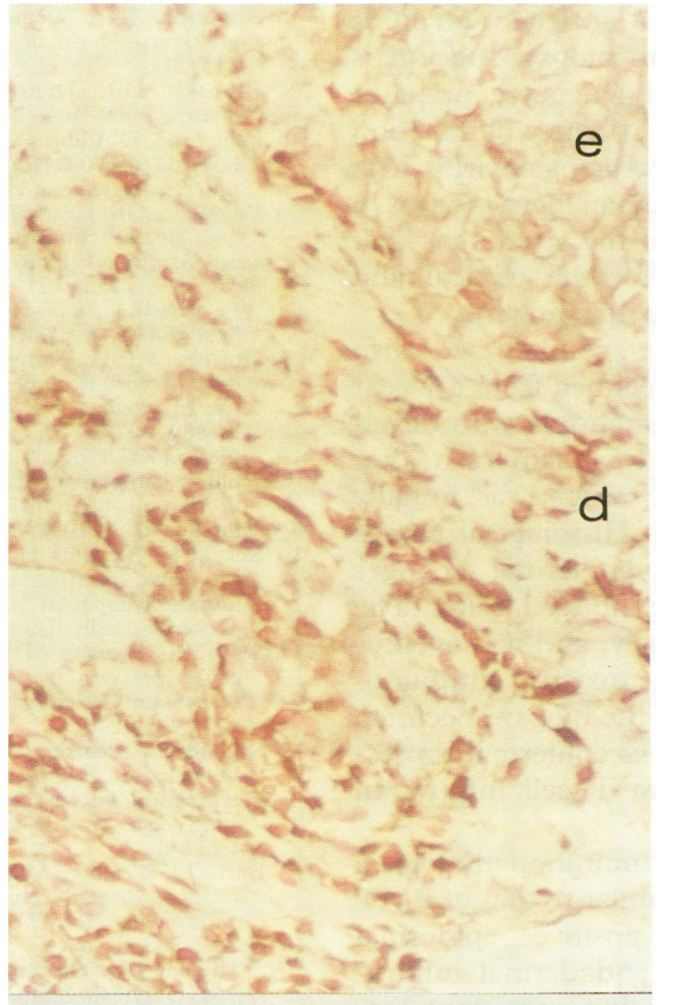

e

emphasises the need for early, accurate diagnosis of this condition. Our experience of nine cases over three years indicates that this condition occurs more often than has been recognised before, and suggests that TAGvHD is underdiagnosed.

We have already shown that immunohistochemical studies are useful in the diagnosis of BMT related GvHD. ${ }^{11}{ }^{12}$ In an earlier study of the immunopathological profile of autologous and allogeneic BMT recipients, seven of 11 allogeneic recipients with GvHD showed diffuse positive expression of HLA-DR by epidermal keratinocytes after BMT. ${ }^{11}$
In the present study we investigated aberrant keratinocyte expression of HLA-DR in nine patients with transfusion associated GvHD. All nine patients showed aberrant expression of HLA-DR by epidermal keratinocytes in biopsy specimens from lesional tissue, indicating that the immunopathological profile of TA-GvHD is similar to that of BMT related GvHD, and that epidermal HLA-DR expression is a useful immunohistochemical marker of both conditions. Furthermore, all four patients with diffuse epidermal expression of HLA-DR died; three of the five patients in whom HLA-DR expression was less strongly positive and more focal survived. This suggests that the extent of epidermal HLA-DR positivity may be an indicator of disease severity in TA-GvHD and so may be of prognostic as well as diagnostic importance.

In our previous study ${ }^{11}$ only one out of 12 autologous recipients showed focal positive epidermal expression of HLA-DR after BMT, having been DR positive before BMT. We have reported elsewhere that many of the autologous BMT recipients analysed in this earlier study had histologically abnormal skin biopsy specimens after BMT, with vacuolar epidermal degeneration seen as a result of the toxicity of the conditioning regimen of drugs. ${ }^{18}$ We have thus previously shown that aberrant keratinocyte expression of HLA-DR is not a feature of generalised drug reactions. This indicates that immunohistochemical staining for HLA-DR is a helpful investigation for the differentiation of GvHD from drug toxicity in pancytopenic patients presenting with unexplained rashes.

We also investigated the distribution of $T$ lymphocyte subsets in lesional tissue in TAGvHD. $T$ cell infiltration of the dermis and epidermis was noted in all nine biopsy specimens. In all nine patients the predominant $T$ cells were of the helper/inducer (CD4 + ) type. Although several workers have postulated that the CD8 $+\mathrm{T}$ cell is the effector cell in GvHD, ${ }^{19}$ infiltration of the dermis and epidermis by $\mathrm{CD} 8+\mathrm{T}$ cells being a common finding in skin biopsy specimens from BMT recipients with $\mathrm{GvHD},{ }^{20}$ we have already shown that a rise in CD8 + cells occurs in the peripheral blood in all BMT recipients, both allogeneic and autologous, irrespective of the presence or absence of GvHD. ${ }^{21} \mathrm{An}$ increase in CD8 + cells in lesional tissue of BMT related GvHD merely reflects the composition of the reconstituting peripheral blood after BMT, and not an active infiltration into lesional tissue. Furthermore, several recent studies have highlighted the role of the CD4 $+\mathrm{T}$ cells in GvHD. ${ }^{22}{ }^{23}$ The predominance of CD4 + cells in lesional tissue from patients with TA-GvHD supports this and provides further evidence for the role of $\mathrm{CD} 4+$ cells in the pathogenesis of GvHD.

To exclude viral exanthem as a cause of the patients' rashes, we also analysed the biopsy specimens for herpes virus infection. Despite extensive investigation, including viral culture, immunohistochemical analysis of skin 
biopsy specimens for viral antigen, and PCR amplification analysis of biopsy specimens and of peripheral blood leucocyte preparations for viral DNA, ${ }^{24}$ no evidence of infection with the herpes viruses cytomegalovirus, herpes simplex virus, or human herpes virus 6 could be found in any of the specimens that would have accounted for the clinical and histological features (data not shown).

In contrast to these results, we also analysed a skin biopsy specimen from a 7 year old girl with Burkitt's lymphoma who developed a diffuse erythematous skin rash after high dose methotrexate, which was initially attributed to TA-GvHD. Histological results proved equivocal, with epidermal changes more suggestive of a drug induced lesion. The rash resolved spontaneously, and was eventually attributed to drug toxicity. Immunohistochemical analysis of the biopsy specimen from this patient showed no epidermal expression of HLA-DR and no T cell infiltration (unpublished data).

In conclusion, the immunopathological profile of TA-GvHD is similar to that of BMT related GvHD, with positive epidermal expression of HLA-DR and dermal infiltration of $T$ lymphocytes being consistent features. The predominant $\mathrm{T}$ cells in TA-GvHD are CD4 + T helper/inducer cells. Immunohistochemical analysis of skin biopsy tissue using antibodies recognising HLA-DR and CD4 + is thus a useful investigation in pancytopenic patients presenting with unexplained rashes. By facilitating early diagnosis and treatment, we suggest that immunohistochemical analysis has an important role in the successful management of TA-GvHD that complicates intensive chemotherapy for malignant disease.

We thank Professor SJ Proctor and Dr PJ Hamilton of the University Department of Haematology, and Professor AW Craft, Dr J Kernahan and Dr MM Reid of the University Department of Child Health, for permission to publish data concerning their patients. We also thank Dr JSM Peiris and Dr CE Taylor of the University Department of Virology, for their help and advice. Dr David Mason of the Leukaemia Research Fund Immunodiagnostics Unit at the John Radcliffe Fund Immunodiagnostics Unit at the John Radcliffe Infirmary, Oxford, kindly donated the anti-CD8 antibody.
The North of England Cancer Research Campaign funded The North

1 Appleton AL, Sviland L. Current thoughts on the pathogenesis of genesis of graft

2 Decoste SD, Boudreaux C, Dover JS. Transfusion-associated graft-vs-host disease in patients with malignancies. Arch Dermatol 1990;26:1324-9.
3 Anderson $\mathrm{KC}$, Weinstein $\mathrm{HJ}$. Transfusion-associated graft-versus-host disease. $N$ Engl $\mathcal{f}$ Med 1990;323: 315-21.

4 Brubaker DB. Transfusion-associated graft-versus-host disease. Hum Pathol 1986;17:1085-8.

5 Fagiolo E, D'Addosio AM. Post-transfusion graft-versushost disease (GvHD): immunopathology and prevention. Haematalogica 1985;70:62-74

6 Vogelsang GB, Hess AD, Santos GW. Acute graft-versushost disease: clinical characteristics in the cyclosoporine era. Medicine 1988;67:163-74.

7 Sakai H, Miyakawa H, Daiguji Y, Masumura Y, Marumo $\mathrm{F}$, Negishi $\mathrm{T}$, et al. Hepatic involvement in graft-versushost disease. Fpn F Med 1990;29:633-6.

8 Greenbaum BH. Transfusion-associated graft-versus-host disease: historical perspectives, incidence and current use of irradiated blood products. $₹$ Clin Oncol 1991; 9:1889-902.

9 Anderson KC, Goodnough LT, Sayers M, et al. Variation in blood component irradiation practice: implications for prevention of transfusion-associated graft-versus-host disease. Blood 1991;77:2096-102.

10 Suzuki K, Akiyama H, Takamoto S, et al. Transfusionassociated graft-versus-host disease in a presumably immunocompetent patient after transfusion of stored packed red cells. Transfusion 1992;32:358-60.

11 Sviland L, Pearson ADJ, Eastham EJ, et al. Class II antigen expression by keratinocytes and enterocytes early feature of graft-versus-host disease. Transplantation 1988;46:402-6.

12 Sviland I Pearson ADJ, Eastham EJ Green MA Malcolm AJ. Expression of Class I and Class II antigen expression by keratinocytes and enterocytes in acute expression by keratinocytes and enterocytes in acute graft-versus

13 Burns LJ, Westberg MW, Burns CP, et al. Acute graft-versus-host disease resulting from normal donor blood transfusions. Acta Haematol 1984;71:270-6.

14 Lerner KG, Kao GF, Storb R, Buckner CD, Clift RA, Thomas ED. Histopathology of graft-versus-host reaction (GvHR) in human recipients of marrow from HLAmatched sibling donors. Trans Proc 1974;6:367-71.

15 Mason DY, Cordell JL, Gaulard P, Tse AGD, Brown MH. Immunohistological detection of human cytotoxic/suppressor T cells using antibodies to a CD8 peptide sequence. $f$ Clin Pathol 1992;45:1084-8.

16 Gerdes J, Becker MHG, Key G, Cattoretti G. Immunohistological detection of tumour growth fraction (Ki-67 antigen) in formalin-fixed and routinely processed tissues. F Pathol 1992;168:85-7.

17 Green MA, Sviland L, Malcolm AJ, Pearson ADJ. An improved method for the detection of membrane antigens in frozen sections by the immunoperoxidase technique. $\mathcal{F}$ Clin Pathol 1989;42:875-80.

18 Sviland L, Pearson ADJ, Eastham EJ, et al. Histological features of skin and rectal biopsy specimens after autologous and allogeneic bone marrow transplantation. $f$ Clin Pathol 1988;41:148-54.

19 Guyotat D, Mauduit G, Chouvet B, et al. A sequential study of histological and immunological changes in the skin after bone marrow transplantation. Transplantation 1986;41:340-2.

20 Korngold R, Sprent J. Surface markers of T cells causing lethal graft-versus-host disease to class I vs class II H-2 differences. F Immunol 1985;135:3004-10.

21 Sviland L, Pearson ADJ, Green MA, et al. Immunopathology of early graft-versus-host disease--a prospective study of skin, rectum and peripheral blood in allogeneic and autologous bone marrow transplant recipients. Transplantation 1991:52:1029-36.

22 Sakamoto H, Michelson J, Jones WK, et al. Lymphocytes with a CD4 + CD8 - CD 3 - phenotype are effectors of experimental cutaneous graft-versus-host disease. Proc Natl Acad Sci USA 1991;88:10890-4.

23 Truitt RL, Atasoylu AA. Contribution of CD4 + and $\mathrm{CD} 8+\mathrm{T}$ cells to graft-versus-host disease and graftversus-leukaemia reactivity after transplantation of verus-leukaemia reactivity after transplantation of Transplant 1991;8:51-8

24 McCarthy AL, Peiris JSM, Taylor CE, et al. Increase in severity of graft-versus-host disease by cytomegalovirus. f Clin Pathol 1993;45:542-4. 